\title{
Dynamic k-Struve Sumudu solutions for fractional kinetic equations
}

\author{
Kottakkaran Sooppy Nisar ${ }^{*}$ and Fethi Bin Muhammad Belgacem²
}

"Correspondence:
n.sooppy@psau.edu.sa
1Department of Mathematics,
College of Arts and Science at Wadi
Aldawaser, Prince Sattam bin
Abdulaziz University, Alkharj, Riyadh
region 11991, Kingdom of Saudi
Arabia
Full list of author information is
available at the end of the article

available at the end of the article

\begin{abstract}
In this present study, we investigate the solutions for fractional kinetic equations involving $\mathrm{k}$-Struve function using the Sumudu transform. The graphical interpretations of the solutions involving $\mathrm{k}$-Struve function and its comparison with generalized Bessel function are given. The methodology and results can be considered and applied to various related fractional problems in mathematical physics.
\end{abstract}

MSC: 26A33; 44A20; 33E12

Keywords: fractional kinetic equations; Sumudu transforms; k-Struve function; fractional calculus

\section{Introduction}

The Struve function $H_{v}(x)$ introduced by Hermann Struve in 1882, defined for $v \in \mathbb{C}$ by

$$
H_{\nu}(x):=\sum_{r=0}^{\infty} \frac{(-1)^{r}}{\Gamma(r+3 / 2) \Gamma\left(r+v+\frac{3}{2}\right)}\left(\frac{x}{2}\right)^{2 r+v+1},
$$

is the particular solutions of the non-homogeneous Bessel differential equations, given by

$$
x^{2} y^{\prime \prime}(x)+x y^{\prime}(x)+\left(x^{2}-v^{2}\right) y(x)=\frac{4\left(\frac{x}{2}\right)^{v+1}}{\sqrt{\pi} \Gamma(v+1 / 2)} .
$$

The homogeneous version of (2) has Bessel functions of the first kind, denoted as $J_{v}(x)$, for solutions, which are finite at $x=0$, when $v$ is a positive fraction and all integers [1], while they tend to diverge for negative fractions $v$. The Struve functions occur in certain areas of physics and applied mathematics, for example, in water-wave and surface-wave problems [2,3], as well as in problems of unsteady aerodynamics [4]. The Struve functions are also important in particle quantum dynamical studies of spin decoherence [5] and nanotubes [6]. For more details about Struve functions, their generalizations and properties, the esteemed reader is invited to consider the references [7-16]. Recently, Nisar et al. [17] introduced and studied various properties of $\mathrm{k}$-Struve function $S_{v, c}^{\mathrm{k}}$ defined by

$$
\mathrm{S}_{\nu, c}^{\mathrm{k}}(x):=\sum_{r=0}^{\infty} \frac{(-c)^{r}}{\Gamma_{\mathrm{k}}\left(r \mathrm{k}+v+\frac{3 \mathrm{k}}{2}\right) \Gamma\left(r+\frac{3}{2}\right)}\left(\frac{x}{2}\right)^{2 r+\frac{v}{\mathrm{k}}+1} .
$$

(c) The Author(s) 2017. This article is distributed under the terms of the Creative Commons Attribution 4.0 International License (http://creativecommons.org/licenses/by/4.0/), which permits unrestricted use, distribution, and reproduction in any medium, provided you give appropriate credit to the original author(s) and the source, provide a link to the Creative Commons license, and indicate if changes were made. 
The Sumudu transform was introduced by Watugala (see $[18,19])$. For more details about the Sumudu transform, see ([1,20-31]). The Sumudu transform over the set of functions

$$
A=\left\{f(t)\left|\exists M, \tau_{1}, \tau_{2}>0,\right| f(t) \mid<M e^{|t| / \tau_{j}} \text {, if } t \in(-1)^{j} \times[0, \infty)\right\}
$$

is defined by

$$
G(u)=S[f(t) ; u]=\int_{0}^{\infty} f(u t) e^{-t} d t, \quad u \in\left(-\tau_{1}, \tau_{2}\right) .
$$

The Sumudu transform of $\mathrm{k}$-Struve function is given by

$$
\begin{aligned}
S\left[\mathrm{~S}_{v, c}^{\mathrm{k}}(x)\right] & =\int_{0}^{\infty} e^{-t} \mathrm{~S}_{v, c}^{\mathrm{k}}(u t) d t \\
& =\int_{0}^{\infty} e^{-t} \sum_{r=0}^{\infty} \frac{(-c)^{r}}{\Gamma_{\mathrm{k}}\left(r \mathrm{k}+v+\frac{3 \mathrm{k}}{2}\right) \Gamma\left(r+\frac{3}{2}\right)}\left(\frac{u t}{2}\right)^{2 r+\frac{v}{\mathrm{k}}+1} d t \\
& =\sum_{r=0}^{\infty} \frac{(-c)^{r}}{\Gamma_{\mathrm{k}}\left(r \mathrm{k}+v+\frac{3 \mathrm{k}}{2}\right) \Gamma\left(r+\frac{3}{2}\right)} \int_{0}^{\infty} e^{-t}\left(\frac{u t}{2}\right)^{\frac{v}{\mathrm{k}}+2 r} d t \\
& =\sum_{r=0}^{\infty} \frac{(-c)^{r} \Gamma\left(\frac{v}{\mathrm{k}}+2 r+2\right)}{\Gamma_{\mathrm{k}}\left(r \mathrm{k}+v+\frac{3 \mathrm{k}}{2}\right) \Gamma\left(r+\frac{3}{2}\right)}\left(\frac{u}{2}\right)^{\frac{v}{\mathrm{k}}+1+2 r} .
\end{aligned}
$$

Now, using

$$
\Gamma_{\mathrm{k}}(\gamma)=\mathrm{k}^{\frac{\gamma}{\mathrm{k}}-1} \Gamma\left(\frac{\gamma}{\mathrm{k}}\right)
$$

we have the following:

$$
S\left[S_{v, c}^{\mathrm{k}}(x)\right]=\sum_{r=0}^{\infty} \frac{(-c)^{r} \Gamma\left(\frac{v}{\mathrm{k}}+2 r+2\right)}{\mathrm{k}^{r+\frac{v}{\mathrm{k}}+\frac{1}{2}} \Gamma\left(r+\frac{v}{\mathrm{k}}+\frac{3}{2}\right) \Gamma\left(r+\frac{3}{2}\right)}\left(\frac{u}{2}\right)^{\frac{v}{\mathrm{k}}+1+2 r} .
$$

Denoting the left-hand side by $G(u)$, we have

$$
\begin{aligned}
G(u) & =S\left[S_{v, c}^{\mathrm{k}}(t) ; u\right] \\
& =\left(\frac{u}{2}\right)^{\frac{v}{\mathrm{k}}+1} k^{-\frac{1}{2}-\frac{v}{\mathrm{k}}}{ }_{2} \Psi_{2}\left[\begin{array}{c}
\left(\frac{v}{\mathrm{k}}+2,2\right),(1,1) \\
\left(\frac{v}{\mathrm{k}}+\frac{3}{2}, 1\right),\left(\frac{3}{2}, 1\right)
\end{array} \mid-\frac{c u^{2}}{4 \mathrm{k}}\right] .
\end{aligned}
$$

Now, using the formula

$$
S^{-1}\left\{u^{v} ; t\right\}=\frac{t^{\nu-1}}{\Gamma(v)}, \quad \Re(v)>1,
$$

we get the inverse Sumudu transform of k-Struve function as

$$
S^{-1}\left[S_{v, c}^{\mathrm{k}}(x)\right]=S^{-1}\left[\sum_{r=0}^{\infty} \frac{(-c)^{r}}{\Gamma_{\mathrm{k}}\left(r \mathrm{k}+v+\frac{3 \mathrm{k}}{2}\right) \Gamma\left(r+\frac{3}{2}\right)}\left(\frac{u}{2}\right)^{\frac{v}{\mathrm{k}}+1+2 r}\right]
$$




$$
\begin{aligned}
& =\sum_{r=0}^{\infty} \frac{(-c)^{r}}{\Gamma_{\mathrm{k}}\left(r \mathrm{k}+v+\frac{3 \mathrm{k}}{2}\right) \Gamma\left(r+\frac{3}{2}\right)}\left(\frac{1}{2}\right)^{\frac{v}{\mathrm{k}}+1+2 r} S^{-1}\left[u^{\frac{v}{\mathrm{k}}+1+2 r}\right] \\
& =\sum_{r=0}^{\infty} \frac{(-c)^{r}\left(\frac{1}{2}\right)^{\frac{v}{\mathrm{k}}+1+2 r}}{\Gamma_{\mathrm{k}}\left(r \mathrm{k}+v+\frac{3 \mathrm{k}}{2}\right) \Gamma\left(r+\frac{3}{2}\right)} \frac{(t)^{\frac{v}{\mathrm{k}}+2 r}}{\Gamma\left(\frac{v}{\mathrm{k}}+1+2 r\right)} .
\end{aligned}
$$

Applying (6) in (10), we get

$$
S^{-1}\left[S_{v, c}^{\mathrm{k}}(x)\right]=\left(\frac{t}{2}\right)^{\frac{v}{\mathrm{k}}} k^{-\frac{1}{2}-\frac{v}{\mathrm{k}}} \Psi_{1}\left[\begin{array}{c}
(1,1) \\
\left(\frac{v}{\mathrm{k}}+\frac{3}{2}, 1\right),\left(\frac{3}{2}, 1\right),\left(\frac{v}{\mathrm{k}}, 2\right)
\end{array} \mid-\frac{c t^{2}}{4 \mathrm{k}}\right] .
$$

In the field of mathematics, many techniques are used to solve various types of problems [32-34]. In this paper, we use the Sumudu transform technique to obtain the solutions of fractional kinetic equations by considering (3). The applications of fractional order calculus are found in many papers (see [35-37]), and it has attracted researchers' attention in various fields [38-46] because of its importance and efficiency. The fractional differential equation between a chemical reaction or a production scheme (such as in birthdeath processes) was established and treated by Haubold and Mathai [47] (also see [21, $38,48])$.

\section{Solution of generalized fractional kinetic equations for k-Struve function}

Let the arbitrary reaction be described by a time-dependent quantity $N=\left(N_{t}\right)$. The rate of change $\frac{d N}{d t}$ is a balance between the destruction rate $\mathfrak{d}$ and the production rate $\mathfrak{p}$ of $\mathrm{N}$, that is, $\frac{d N}{d t}=-\mathfrak{d}+\mathfrak{p}$. Generally, destruction and production depend on the quantity $N$ itself, that is,

$$
\frac{d N}{d t}=-\mathfrak{d}\left(N_{t}\right)+\mathfrak{p}\left(N_{t}\right)
$$

where $N_{t}$ is described by $N_{t}\left(t^{*}\right)=N\left(t-t^{*}\right), t^{*}>0$. Another form of (12) is

$$
\frac{d N_{i}}{d t}=-c_{i} N_{i}(t)
$$

with $N_{i}(t=0)=N_{0}$, which is the number of density of species $i$ at time $t=0$ and $c_{i}>0$. The solution of (13) is

$$
N_{i}(t)=N_{0} e^{-c_{i} t}
$$

Integrating (13) gives

$$
N(t)-N_{0}=-c \cdot{ }_{0} D_{t}^{-1} N(t)
$$

where ${ }_{0} D_{t}^{-1}$ is the particular case of the Riemann-Liouville integral operator and $c$ is a constant. The fractional form of (15) due to [47] is

$$
N(t)-N_{0}=-c_{0}^{v} D_{t}^{-v} N(t)
$$


where ${ }_{0} D_{t}^{-v}$ is defined as

$$
{ }_{0} D_{t}^{-v} f(t)=\frac{1}{\Gamma(v)} \int_{0}^{t}(t-s)^{v-1} f(s) d s, \quad \Re(v)>0 .
$$

Suppose that $f(t)$ is a real- or complex-valued function of the (time) variable $t>0$ and $\mathrm{s}$ is a real or complex parameter. The Laplace transform of $f(t)$ is defined by

$$
F(p)=L[f(t): p]=\int_{0}^{\infty} e^{-p t} f(t) d t, \quad \Re(p)>0 .
$$

The Mittag-Leffler functions $E_{\rho}(z)$ (see [49]) and $E_{\rho, \lambda}(x)$ [50] are defined respectively as follows:

$$
\begin{aligned}
& E_{\rho}(z)=\sum_{n=0}^{\infty} \frac{z^{n}}{\Gamma(\rho n+1)} \quad(z, \rho \in \mathbb{C} ;|z|<0, \Re(\rho)>0) . \\
& E_{\rho, \lambda}(x)=\sum_{n=0}^{\infty} \frac{x^{n}}{\Gamma(\rho n+\lambda)} \quad(z, \rho, \lambda \in \mathbb{C} ; \Re(\rho)>0, \Re(\lambda)>0) .
\end{aligned}
$$

Theorem 1 If $d>0, v>0, \mu, c, t \in \mathbb{C}$ and $\mu>-\frac{3}{2} \mathrm{k}$, then the solution of the generalized fractional kinetic equation

$$
N(t)=N_{0} \mathrm{~S}_{\mu, c}^{\mathrm{k}}\left(d^{v} t^{\nu}\right)-d^{v}{ }_{0} D_{t}^{-v} N(t)
$$

is given by the following formula:

$$
\begin{aligned}
N(t)= & N_{0} \sum_{r=0}^{\infty} \frac{(-c)^{r} \Gamma\left[v\left(2 r+\frac{\mu}{\mathrm{k}}+1\right)+1\right]}{\Gamma_{\mathrm{k}}\left(r \mathrm{k}+\mu+\frac{3}{2} \mathrm{k}\right) \Gamma\left(r+\frac{3}{2}\right)} \frac{1}{t}\left(\frac{d^{v} t^{\nu}}{2}\right)^{2 r+\frac{\mu}{\mathrm{k}}+1} \\
& \times E_{v, v\left(2 r+\frac{\mu}{\mathrm{k}}\right)+1}\left(-d^{v} t^{\nu}\right)
\end{aligned}
$$

where $E_{v, v\left(2 r+\frac{\mu}{k}\right)+1}\left(-d^{v} t^{\nu}\right)$ is given in $(20)$.

Proof The Sumudu transform of Riemann-Liouville fractional integral operators is given by

$$
S\left\{{ }_{0} D_{t}^{-v} f(t) ; u\right\}=u^{v} G(u),
$$

where $G(u)$ is defined in (8). Now, applying the Sumudu transform to both sides of (21) and applying the definition of $\mathrm{k}$-Struve function given in (3), we have

$$
\begin{aligned}
N^{*}(u) & =S[N(t) ; u] \\
& =N_{0} S\left[\mathrm{~S}_{\mu, c}^{\mathrm{k}}\left(d^{v} t^{\nu}\right) ; u\right]-d^{\nu} S\left[{ }_{0} D_{t}^{-v} N(t) ; u\right] \\
& =N_{0}\left[\int_{0}^{\infty} e^{-p t} \sum_{r=0}^{\infty} \frac{(-c)^{r}}{\Gamma_{\mathrm{k}}\left(r \mathrm{k}+\mu+\frac{3}{2} \mathrm{k}\right) \Gamma\left(r+\frac{3}{2}\right)}\left(\frac{d^{\nu}(u t)^{v}}{2}\right)^{2 r+\frac{\mu}{\mathrm{k}}+1} d t\right]
\end{aligned}
$$




$$
-d^{v} u^{v} N^{*}(u)
$$

where

$$
S\left\{t^{\mu-1}\right\}=u^{\mu-1} \Gamma(\mu) .
$$

By rearranging terms, we get

$$
\begin{aligned}
N^{*}(u) & +d^{v} u^{v} N^{*}(u) \\
= & N_{0} \sum_{r=0}^{\infty} \frac{(-c)^{r}}{\Gamma_{\mathrm{k}}\left(r \mathrm{k}+\mu+\frac{3}{2} \mathrm{k}\right) \Gamma\left(r+\frac{3}{2}\right)}\left(\frac{d^{v}}{2}\right)^{2 r+\frac{\mu}{\mathrm{k}}+1} \\
& \times \int_{0}^{\infty} e^{-t}(u t)^{v\left(2 r+\frac{\mu}{\mathrm{k}}+1\right)} d t \\
= & N_{0} \sum_{r=0}^{\infty} \frac{(-c)^{r} \Gamma\left[v\left(2 r+\frac{\mu}{k}+1\right)+1\right]}{\Gamma_{\mathrm{k}}\left(r \mathrm{k}+\mu+\frac{3}{2} \mathrm{k}\right) \Gamma\left(r+\frac{3}{2}\right)}\left(\frac{u^{v} d^{v}}{2}\right)^{2 r+\frac{\mu}{\mathrm{k}}+1} .
\end{aligned}
$$

Therefore

$$
\begin{aligned}
N^{*}(u) & =N_{0} \sum_{r=0}^{\infty} \frac{(-c)^{r} \Gamma\left[v\left(2 r+\frac{\mu}{k}+1\right)+1\right]}{\Gamma_{\mathrm{k}}\left(r \mathrm{k}+\mu+\frac{3}{2} \mathrm{k}\right) \Gamma\left(r+\frac{3}{2}\right)}\left(\frac{d^{\nu}}{2}\right)^{2 r+\frac{\mu}{\mathrm{k}}+1} \\
& \times\left\{u^{\nu\left(2 r+\frac{\mu}{\mathrm{k}}+1\right)} \sum_{n=0}^{\infty}\left[-(d u)^{\nu}\right]^{n}\right\} .
\end{aligned}
$$

Taking the inverse Sumudu transform of (26) and by using

$$
S^{-1}\left\{u^{\nu} ; t\right\}=\frac{t^{\nu-1}}{\Gamma(\nu)}, \quad \Re(\nu)>0,
$$

we have

$$
\begin{aligned}
S^{-1}\left\{N^{*}(u)\right\}= & N_{0} \sum_{r=0}^{\infty} \frac{(-c)^{r} \Gamma\left[v\left(2 r+\frac{\mu}{k}+1\right)+1\right]}{\Gamma_{\mathrm{k}}\left(r \mathrm{k}+\mu+\frac{3}{2} \mathrm{k}\right) \Gamma\left(r+\frac{3}{2}\right)}\left(\frac{d^{v}}{2}\right)^{2 r+\frac{\mu}{\mathrm{k}}+1} \\
& \times S^{-1}\left\{\sum_{n=0}^{\infty}(-1)^{n}(d)^{v n} u^{\nu\left(2 r+\frac{\mu}{\mathrm{k}}+n+1\right)}\right\}
\end{aligned}
$$

which gives

$$
\begin{aligned}
N(t)= & N_{0} \sum_{r=0}^{\infty} \frac{(-c)^{r} \Gamma\left[v\left(2 r+\frac{\mu}{\mathrm{k}}+1\right)+1\right]}{\Gamma_{\mathrm{k}}\left(r \mathrm{k}+\mu+\frac{3}{2} \mathrm{k}\right) \Gamma\left(r+\frac{3}{2}\right)}\left(\frac{d^{v}}{2}\right)^{2 r+\frac{\mu}{\mathrm{k}}+1} \\
& \times\left\{\sum_{n=0}^{\infty}(-1)^{n}(d)^{\nu n} \frac{t^{\nu\left(2 r+\frac{\mu}{\mathrm{k}}+n+1\right)-1}}{\Gamma\left[v\left(2 r+\frac{\mu}{\mathrm{k}}+n+1\right)\right]}\right\} \\
= & N_{0} \sum_{r=0}^{\infty} \frac{(-c)^{r} \Gamma\left[v\left(2 r+\frac{\mu}{\mathrm{k}}+1\right)+1\right]}{\Gamma_{\mathrm{k}}\left(r \mathrm{k}+\mu+\frac{3}{2} \mathrm{k}\right) \Gamma\left(r+\frac{3}{2}\right)} \frac{1}{t}\left(\frac{d^{v} t^{\nu}}{2}\right)^{2 r+\frac{\mu}{\mathrm{k}}+1}
\end{aligned}
$$




$$
\begin{aligned}
& \quad \times\left\{\sum_{n=0}^{\infty}(-1)^{n}(d)^{v n} \frac{t^{\nu}}{\Gamma\left[v\left(2 r+\frac{\mu}{\mathrm{k}}+n+1\right)\right]}\right\} \\
& =N_{0} \sum_{r=0}^{\infty} \frac{(-c)^{r} \Gamma\left[v\left(2 r+\frac{\mu}{\mathrm{k}}+1\right)+1\right]}{\Gamma_{\mathrm{k}}\left(r \mathrm{k}+\mu+\frac{3}{2} \mathrm{k}\right) \Gamma\left(r+\frac{3}{2}\right)} \frac{1}{t}\left(\frac{d^{v} t^{\nu}}{2}\right)^{2 r+\frac{\mu}{\mathrm{k}}+1} \\
& \quad \times E_{v, v\left(2 r+\frac{\mu}{\mathrm{k}}\right)+1}\left(-d^{v} t^{\nu}\right),
\end{aligned}
$$

which is the desired result.

Corollary 1 If we put $\mathrm{k}=1$ in (22), then we get the solution of involving the classical Struve function as follows: If $d>0, v>0, \mu, c, t \in \mathbb{C}$ and $\mu>-\frac{3}{2}$, then the equation

$$
N(t)=N_{0} S_{\mu, c}^{1}\left(d^{v} t^{\nu}\right)-d^{v}{ }_{0} D_{t}^{-v} N(t)
$$

has the solution

$$
\begin{aligned}
N(t)= & N_{0} \sum_{r=0}^{\infty} \frac{(-c)^{r} \Gamma[v(2 r+\mu+1)+1]}{\Gamma\left(r+\mu+\frac{3}{2}\right) \Gamma\left(r+\frac{3}{2}\right)} \frac{1}{t}\left(\frac{d^{v} t^{v}}{2}\right)^{2 r+\mu+1} \\
& \times E_{v, v(2 r+\mu)+1}\left(-d^{v} t^{\nu}\right) .
\end{aligned}
$$

Theorem 2 If $\mathfrak{a}>0, d>0, v>0, c, \mu, t \in \mathbb{C}, \mathfrak{a} \neq d$ and $\mu>-\frac{3}{2} k$, then the solution of equation

$$
N(t)=N_{0} S_{\mu, c}^{\mathrm{k}}\left(d^{\nu} t^{\nu}\right)-\mathfrak{a}^{\nu}{ }_{0} D_{t}^{-v} N(t)
$$

is given by

$$
\begin{aligned}
N(t)= & N_{0} \sum_{r=0}^{\infty} \frac{(-c)^{r} \Gamma\left[v\left(2 r+\frac{\mu}{\mathrm{k}}+1\right)+1\right]}{\Gamma_{\mathrm{k}}\left(r \mathrm{k}+\mu+\frac{3}{2} \mathrm{k}\right) \Gamma\left(r+\frac{3}{2}\right)} \frac{1}{t}\left(\frac{d^{\nu} t^{\nu}}{2}\right)^{2 r+\frac{\mu}{\mathrm{K}}+1} \\
& \times E_{\nu, \nu\left(2 r+\frac{\mu}{\mathrm{k}}\right)+1}\left(-\mathfrak{a}^{v} t^{\nu}\right)
\end{aligned}
$$

where $E_{\nu, \nu\left(2 r+\frac{\mu}{K}\right)+1}(\cdot)$ is given in $(20)$.

Proof Theorem 2 can be proved in parallel with the proof of Theorem 1. So the details of proofs are omitted.

Corollary 2 By putting $\mathrm{k}=1$ in Theorem 2, we get the solution of fractional kinetic equation involving classical Struve function: If $\mathfrak{a}>0, d>0, v>0, c, \mu, t \in \mathbb{C}, \mathfrak{a} \neq d$ and $\mu>-\frac{3}{2}$, then the equation

$$
N(t)=N_{0} S_{\mu, c}^{1}\left(d^{\nu} t^{\nu}\right)-\mathfrak{a}^{v}{ }_{0} D_{t}^{-v} N(t)
$$

is given by the following formula:

$$
N(t)=N_{0} \sum_{r=0}^{\infty} \frac{(-c)^{r} \Gamma[v(2 r+\mu+1)+1]}{\Gamma\left(r+\mu+\frac{3}{2}\right) \Gamma\left(r+\frac{3}{2}\right)} \frac{1}{t}\left(\frac{d^{v} t^{\nu}}{2}\right)^{2 r+\mu+1} E_{v, \nu(2 r+\mu)+1}\left(-\mathfrak{a}^{v} t^{\nu}\right) .
$$


Theorem 3 If $d>0, v>0, c, \mu, t \in \mathbb{C}$ and $\mu>-\frac{3}{2} \mathrm{k}$, then the solution of

$$
N(t)=N_{0} \mathrm{~S}_{\mu, c}^{\mathrm{k}}\left(t^{\nu}\right)-d^{\nu}{ }_{0} D_{t}^{-\nu} N(t)
$$

is given by

$$
\begin{aligned}
N(t)= & N_{0} \sum_{r=0}^{\infty} \frac{(-c)^{r} \Gamma\left[v\left(2 r+\frac{\mu}{\mathrm{k}}+1\right)+1\right]}{\Gamma_{\mathrm{k}}\left(r \mathrm{k}+\mu+\frac{3}{2} \mathrm{k}\right) \Gamma\left(r+\frac{3}{2}\right)} \frac{1}{t}\left(\frac{t}{2}\right)^{2 r+\frac{\mu}{\mathrm{k}}+1} \\
& \times E_{v, v\left(2 r+\frac{\mu}{\mathrm{k}}\right)+1}\left(-d^{\nu} t^{\nu}\right)
\end{aligned}
$$

where $E_{\nu, \nu\left(2 r+\frac{\mu}{k}\right)+1}(\cdot)$ is given in $(20)$.

Proof The proofs of Theorem 3 would run parallel to those of Theorem 1.

Corollary 3 If we set $\mathrm{k}=1$, then (35) is reduced as follows: If $d>0, v>0, c, \mu, t \in \mathbb{C}$ and $\mu>-\frac{3}{2}$, then the solution of the following equation

$$
N(t)=N_{0} S_{\mu, c}^{1}\left(t^{\nu}\right)-d^{v}{ }_{0} D_{t}^{-v} N(t)
$$

is given by the formula

$$
\begin{aligned}
N(t)= & N_{0} \sum_{r=0}^{\infty} \frac{(-c)^{r} \Gamma[v(2 r+\mu+1)+1]}{\Gamma\left(r+\mu+\frac{3}{2}\right) \Gamma\left(r+\frac{3}{2}\right)} \frac{1}{t}\left(\frac{t}{2}\right)^{2 r+\mu+1} \\
& \times E_{v, v(2 r+\mu)+1}\left(-d^{\nu} t^{\nu}\right) .
\end{aligned}
$$

\section{Graphical interpretation}

In this section, first we plot the graphs of our solutions of the fractional kinetic equation, which is established in (22). In each graph, we give three solutions of the results on the basis of assigning different values to the parameters. In Figure 1 , we take $\mathrm{k}=1$ and $v=0.5,0.7,0.9,1,1.5$. Similarly, Figures 2,3 are plotted respectively by taking $\mathrm{k}=2$ and 3. Figures 4, 5, 6 are plotted by considering the solution given in (35) by taking $v=0.5,0.7,0.9,1,1.5$ and $k=1,2,3$. Other than $v$ and $k$, all other parameters are fixed by 1 . Observing these figures, we see that $N(t)>0$ for $t>0$ and the behavior of the solutions for different parameters and time interval can be studied and observed very easily. In this study, we choose first 50 terms of Mittag-Leffler function and first 50 terms of our solutions to plot the graphs. Also, the comparison between solutions of generalized fractional kinetic equations involving generalized Bessel function (solid green line) and k-Struve function (dashed red line) are shown in Figure 7.

\section{Conclusion}

In this work, we have established the solution of fractional kinetic equation involving $\mathrm{k}$ Struve function with the help of the Sumudu transform and provided its graphical interpretations. From the close relationship of the $\mathrm{k}$-Struve function with other special functions, one can easily construct various known and new fractional kinetic equations. 


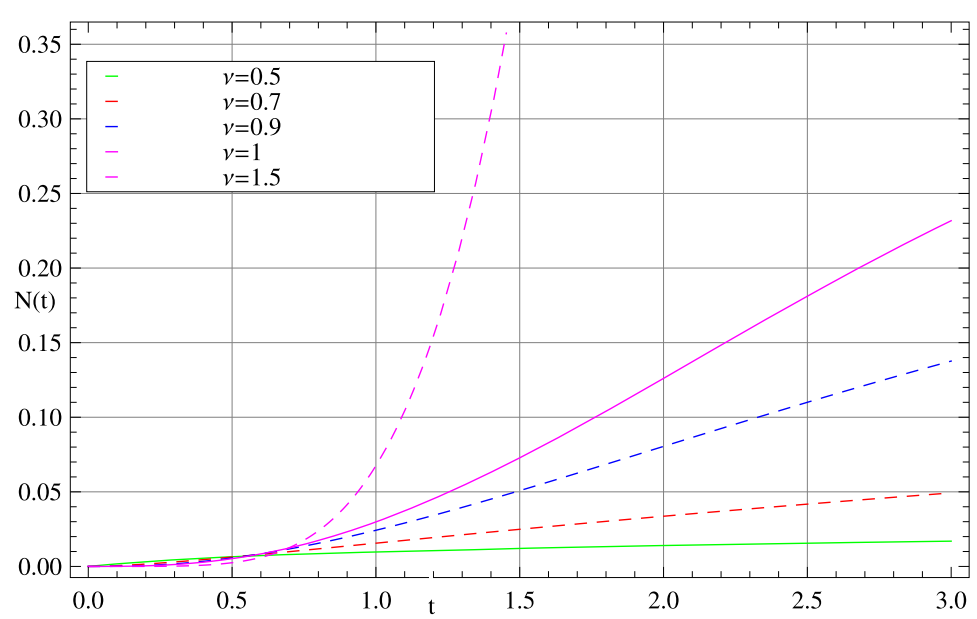

Figure 1 Solution (22) for $N(t), \mathrm{k}=1$.

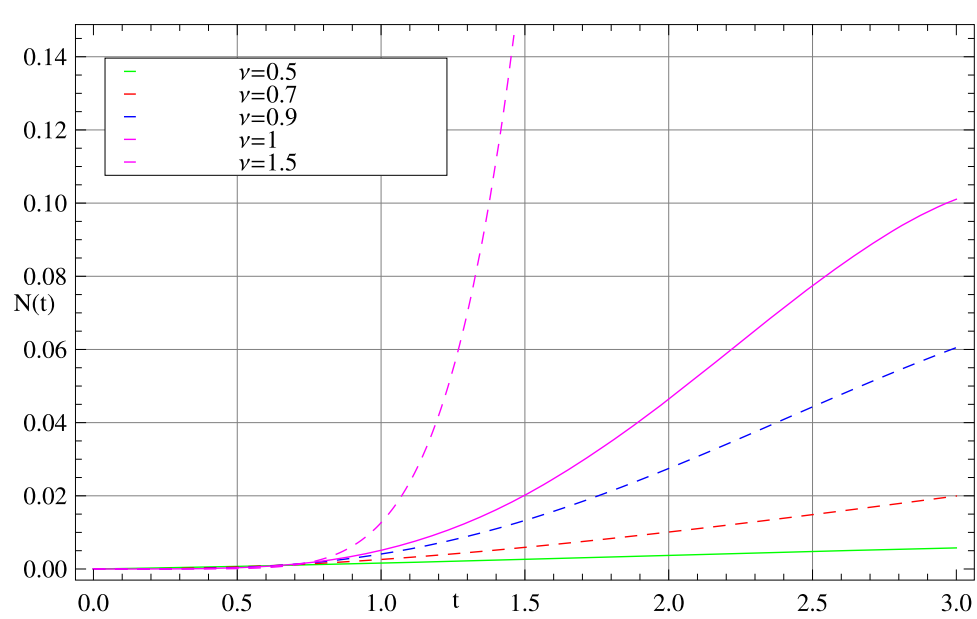

Figure 2 Solution (22) for $N(t), \mathrm{k}=2$.

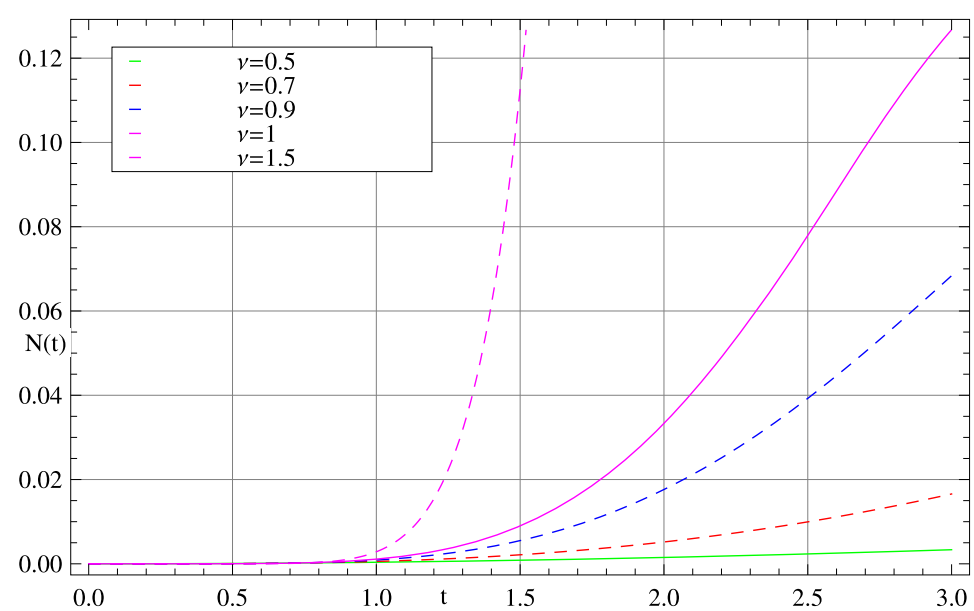

Figure 3 Solution (22) for $N(t), \mathrm{k}=3$. 


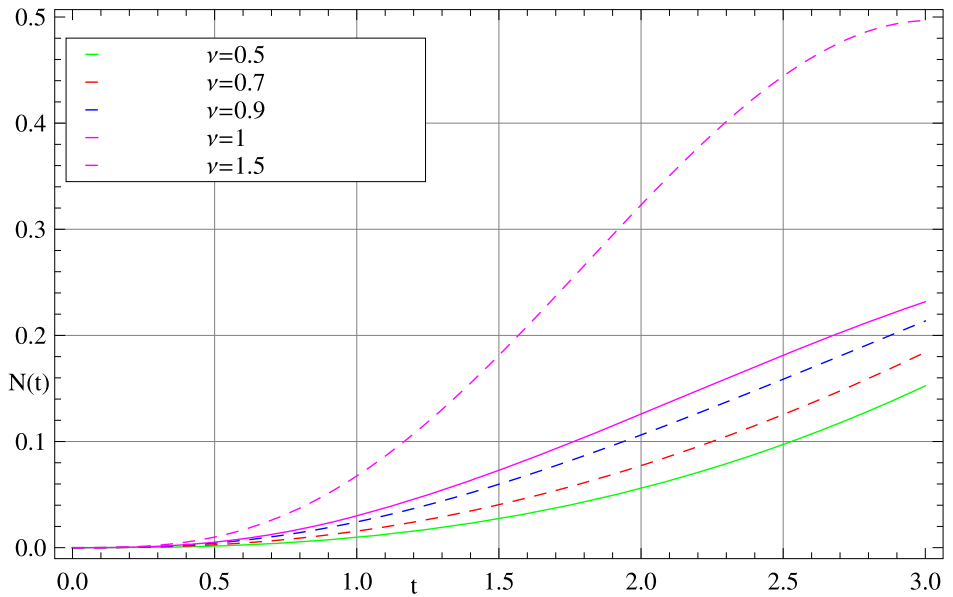

Figure 4 Solution (35) for $N(t), \mathrm{k}=1$.

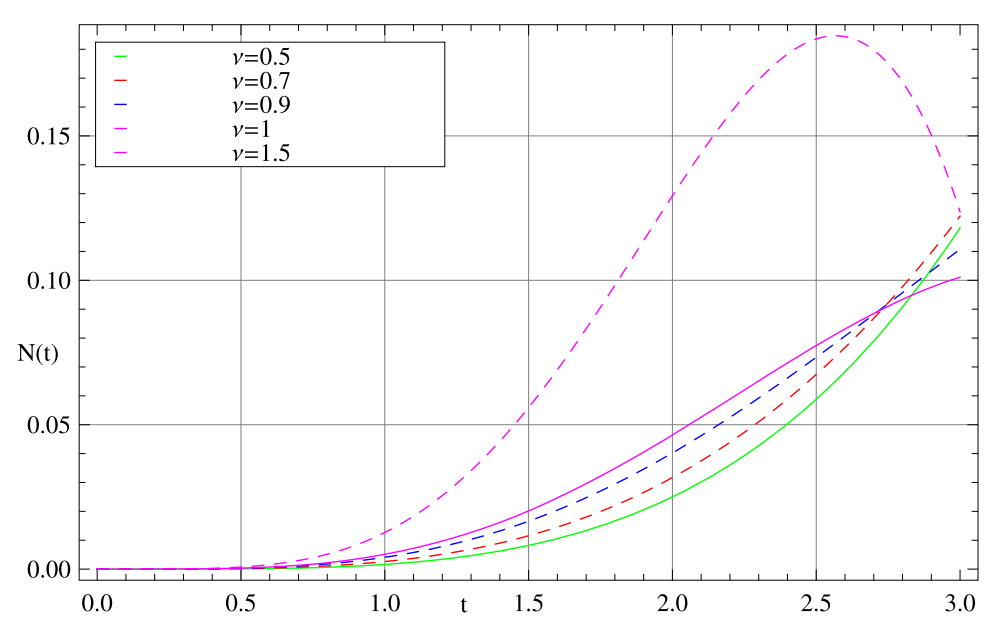

Figure 5 Solution (35) for $N(t), \mathrm{k}=2$.

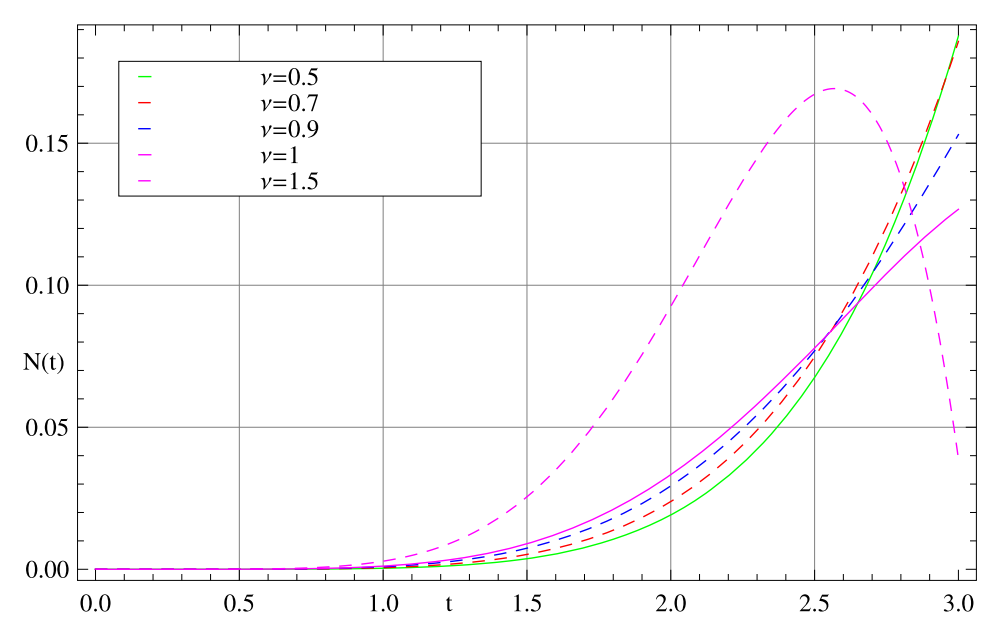

Figure 6 Solution (35) for $N(t), \mathrm{k}=3$. 


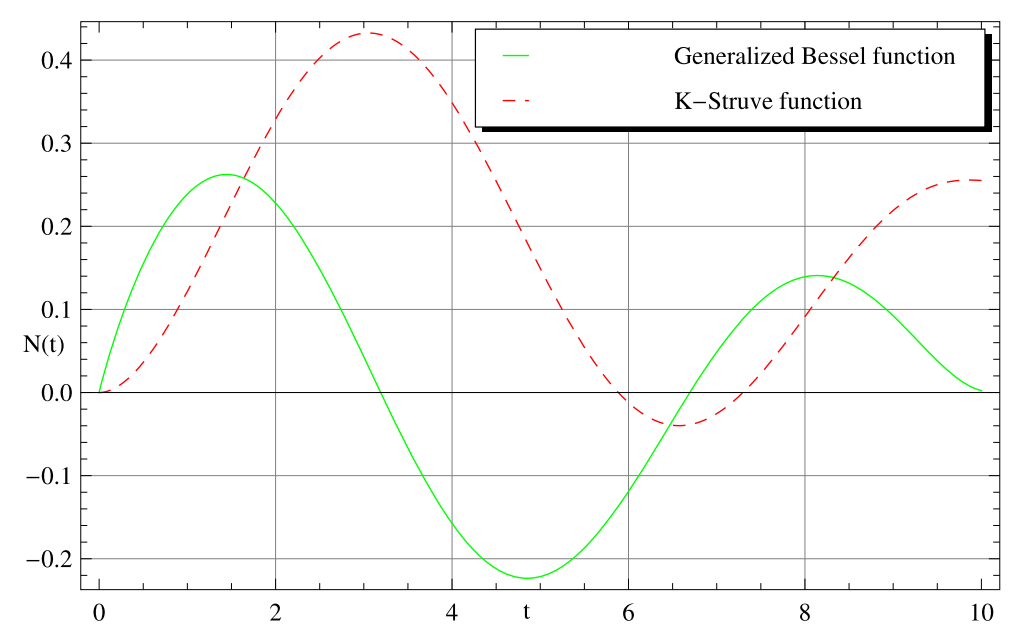

Figure 7 Comparison between solutions (22) and (18) of [51].

\section{Competing interests}

The authors declare that they have no competing interests.

\section{Authors' contributions}

The authors have contributed equally to this manuscript. They read and approved the final manuscript.

\section{Author details}

'Department of Mathematics, College of Arts and Science at Wadi Aldawaser, Prince Sattam bin Abdulaziz University, Alkharj, Riyadh region 11991, Kingdom of Saudi Arabia. ${ }^{2}$ Department of Mathematics, Faculty of Basic Education, PAAET, Al-Ardhiya, Kuwait.

\section{Publisher's Note}

Springer Nature remains neutral with regard to jurisdictional claims in published maps and institutional affiliations.

Received: 29 May 2017 Accepted: 10 October 2017 Published online: 23 October 2017

\section{References}

1. Belgacem, FBM: Applications with the Sumudu transform to Bessel functions and equations. Appl. Math. Sci. 4 3665-3686 (2010)

2. Ahmadi, AL, Widnall, SE: Unsteady lifting-line theory as a singular-perturbation problem. J. Fluid Mech. 153, 59-81 (1985)

3. Hirata, MH: Flow near the bow of a steadily turning ship. J. Fluid Mech. 71(2), 283-291 (1975)

4. Shaw, DC: Perturbational results for diffraction of water-waves by nearly-vertical barriers. IMA J. Appl. Math. 34, 99-117 (1985)

5. Shao, J, Hanggi, P: Decoherent dynamics of a two-level system coupled to a sea of spins. Phys. Rev. Lett. 81(26), 5710-5713 (1998)

6. Pedersen, TG: Variational approach to excitons in carbon nanotubes. Phys. Rev. B 67, Article ID 073401 (2003). doi:10.1103/PhysRevB.67.073401

7. Orhan, H, Yagmur, N: Geometric properties of generalized Struve functions. An. Ştiinţ. Univ. 'Al.I. Cuza' laşi, Mat. (2014). doi:10.2478/aicu-2014-0007

8. Yagmur, N, Orhan, H: Starlikeness and convexity of generalized Struve functions. Abstr. Appl. Anal. 2013, Article ID 954513 (2013). doi:10.1155/2013/954513

9. Bhowmick, KN: Some relations between a generalized Struve's function and hypergeometric functions. Vijnana Parishad Anusandhan Patrika 5, 93-99 (1962)

10. Bhowmick, KN: A generalized Struve's function and its recurrence formula. Vijnana Parishad Anusandhan Patrika 6 1-11 (1963)

11. Kanth, BN: Integrals involving generalized Struve's function. Nepali Math. Sci. Rep. 6, 61-64 (1981)

12. Singh, RP: Generalized Struve's function and its recurrence relations. Ranchi Univ. Math. J. 5, 67-75 (1974)

13. Singh, RP: Generalized Struve's function and its recurrence equation. Vijnana Parishad Anusandhan Patrika 28(3), 287-292 (1985)

14. Singh, RP: Some integral representation of generalized Struve's function. Math. Educ. 22(3), $91-94$ (1988)

15. Singh, RP: On definite integrals involving generalized Struve's function. Math. Educ. 22(2), $62-66$ (1988)

16. Singh, RP: Infinite integrals involving generalized Struve function. Math. Educ. 23(1), 30-36 (1989)

17. Nisar, KS, Mondal, SR, Choi, J: Certain inequalities involving the k-Struve function. J. Inequal. Appl. 17, Article ID 71 (2017). doi:10.1186/s13660-017-1343-x 
18. Watugala, GK: Sumudu transform: a new integral transform to solve differential equations and control engineering problems. Int. J. Math. Educ. Sci. Technol. 24, 35-43 (1993)

19. Watugala, GK: The Sumudu transform for functions of two variables. Math. Eng. Ind. 8, 293-302 (2002)

20. Asiru, MA: Sumudu transform and the solution of integral equation of convolution type. Int. J. Math. Educ. Sci. Technol. 32, 906-910 (2001)

21. Belgacem, FBM, Karaballi, AA, Kalla, SL: Analytical investigations of the Sumudu transform and applications to integral production equations. J. Math. Probl. Eng. 3, 103-118 (2003)

22. Belgacem, FBM, Karaballi, AA: Sumudu transform fundamental properties investigations and applications. J. Appl. Math. Stoch. Anal. 2006, Article ID 91083 (2006). doi:10.1155/JAMSA/2006/91083

23. Belgacem, FBM: Introducing and analyzing deeper Sumudu properties. Nonlinear Stud. 13, 23-42 (2006)

24. Belgacem, FBM: Sumudu applications to Maxwell's equations. PIERS Online 5, 355-360 (2009)

25. Belgacem, FBM, Silambarasan, R: A distinctive Sumudu treatment of trigonometric functions. J. Comput. Appl. Math. 312, 74-81 (2017)

26. Belgacem, FBM, Al-Shemas, EH, Silambarasan, R: Sumudu computation of the transient magnetic field in a Lossy medium. Appl. Math. Inf. Sci. 6, 1-9 (2016)

27. Chaurasia, VBL, Dubey, RS, Belgacem, FBM: Fractional radial diffusion equation analytical solution via Hankel and Sumudu transforms. Int. J. Math. Eng. Sci. Aerosp. 3(2), 179-188 (2012)

28. Hussain, MGM, Belgacem, FBM: Transient solutions of Maxwell's equations based on Sumudu transformation. J. Progr. Electromagn. Res. (PIER) 74, 273-289 (2007)

29. Atangana, A, Baleanu, D: Nonlinear fractional Jaulent-Miodek and Whitham-Broer-Kaup equations within Sumudu transform. Abstr. Appl. Anal. 2013, Article ID 160681 (2013). doi:10.1155/2013/160681

30. Srivastava, HM, Golmankhaneh, AK, Baleanu, D, Yang, X-J: Local fractional Sumudu transform with application to IVPS on Cantor sets. Abstr. Appl. Anal. 2014, Article ID 620529 (2014)

31. Ziane, D, Baleanu, D, Belghaba, K, Hamdi Cherif, M: Local fractional sumudu decomposition method for linear partial differential equations with local fractional derivative. J. King Saud Univ., Sci. (2017). doi:10.1016/j.jksus.2017.05.002

32. Marin, M: On weak solutions in elasticity of dipolar bodies with voids. J. Comput. Appl. Math. 82(1-2), $291-297$ (1997)

33. Marin, M: Harmonic vibrations in thermoelasticity of microstretch materials. J. Vib. Acoust. ASME 132(4), 044501-044506 (2010). doi:10.1115/1.4000971

34. Sharma, K, Marin, M: Effect of distinct conductive and thermodynamic temperatures on the reflection of plane waves in micropolar elastic half-space. UPB Sci. Bull., Ser. A, Appl. Math. Phys. 75(2), 121-132 (2013)

35. Yang, X-J: Fractional derivatives of constant and variable orders applied to anomalous relaxation models in heat-transfer problems. Therm. Sci. 21(3), 1161-1171 (2017)

36. Yang, X-J, Srivastava, HM, Tenreiro Machado, JA: A new fractional derivative without singular kernel: application to the modelling of the steady heat flow. Therm. Sci. 20(2), 753-756 (2016)

37. Yang, X-J, Tenreiro Machado, JA: A new fractional operator of variable order: application in the description of anomalous diffusion. Phys. A, Stat. Mech. Appl. 481, 276-283 (2017)

38. Gupta, VG, Sharma, B, Belgacem, FBM: On the solutions of generalized fractional kinetic equations. Appl. Math. Sci. 5(19), 899-910 (2011)

39. Nisar, KS, Purohit, SD, Mondal, SR: Generalized fractional kinetic equations involving generalized Struve function of the first kind. J. King Saud Univ., Sci. 28(2), 167-171 (2016)

40. Saichev, A, Zaslavsky, M: Fractional kinetic equations: solutions and applications. Chaos 7, 753-764 (1997)

41. Saxena, RK, Mathai, AM, Haubold, HJ: On fractional kinetic equations. Astrophys. Space Sci. 282, $281-287$ (2002)

42. Saxena, RK, Mathai, AM, Haubold, HJ: On generalized fractional kinetic equations. Physica A 344, 657-664 (2004)

43. Saxena, RK, Mathai, AM, Haubold, HJ: Solution of generalized fractional reaction-diffusion equations. Astrophys. Space Sci. 305, 305-313 (2006)

44. Saxena, RK, Kalla, SL: On the solutions of certain fractional kinetic equations. Appl. Math. Comput. 199, 504-511 (2008)

45. Zaslavsky, GM: Fractional kinetic equation for Hamiltonian chaos. Physica D 76, 110-122 (1994)

46. Katatbeh, QK, Belgacem, FBM: Applications of the Sumudu transform to fractional differential equations. Nonlinear Stud. 18(1), 99-112 (2011)

47. Haubold, HJ, Mathai, AM: The fractional kinetic equation and thermonuclear functions. Astrophys. Space Sci. 327, 53-63 (2000)

48. Chaurasia, VBL, Pandey, SC: On the new computable solution of the generalized fractional kinetic equations involving the generalized function for the fractional calculus and related functions. Astrophys. Space Sci. 317, 213-219 (2008)

49. Mittag-Leffler, GM: Sur la representation analytiqie d'une fonction monogene cinquieme note. Acta Math. 29, 101-181 (1905)

50. Wiman, A: Uber den fundamental satz in der theorie der funktionen $E_{\alpha}(z)$. Acta Math. 29, 191-201 (1905)

51. Kumar, D, Purohit, SD, Secer, A, Atangana, A: On generalized fractional kinetic equations involving generalized Bessel function of the first kind. Math. Probl. Eng. 2015, Article ID 289387 (2015). doi:10.1155/2015/289387 